15 Nichol G, Stiell IG, Hebert P, Wells GA, Vandemheen K, Laupacis A. What is the quality of life for survivors of cardiac arrest? A prospective study. Acad Emerg Med 1999;6:95-102

16 Diggory P, Cauchi L, Griffith D, Jones V, Lawrence E, Mehta A, et al. The influence of new guidelines on cardiopulmonary resuscitation (CPR) decisions. Five cycles of audit of a clerk proforma which included a resuscitation decision. Resuscitation 2003;56:159-65.

17 Department for Constitutional Affairs. Mental capacity act. London, 2005. 18 R (Burke) v General Medical Council: Queen's Bench Division (Administrative court), 2004.

19 O'Brien LA, Grisso JA, Maislin G, LaPann K, Krotki KP, Greco PJ, et al Nursing home residents' preferences for life-sustaining treatments. JAMA 1995;274:1775-9.

20 Gjerdingen DK, Neff JA, Wang M, Chaloner K. Older persons' opinions about life-sustaining procedures in the face of dementia. Arch Fam Med $1999 ; 8: 421-5$.
21 Laakkonen M-L, Pitkala KH, Strandberg TE, Berglind S, Tilvis RS. Older people's reasoning for resuscitation preferences and their role in the decision-making process. Resuscitation 2005;65:165

22 Von Mises L. Human action: a treatise on economics. 4th ed. Irvington: Foundation for Economic Education, 1996.

23 Dingwall R, Shuttleworth A. CPR: Is it cruel or kind? Nursing Times 2002:98:36-8.

24 Swor R, Compton S. Estimating cost-effectiveness of mass cardiopulmonary resuscitation training strategies to improve survival from cardiac arrest in private locations. Prehosp Emerg Care 2004;8:420-3.

25 Nichol G, Valenzuela T, Roe D, Clark L, Huszti E, Wells GA. Cost effectiveness of defibrillation by targeted responders in public settings. Circulation 2003;108:697-703

\title{
Health economics
}

\section{Using economics to set pragmatic and ethical priorities}

\author{
Stuart Peacock, Danny Ruta, Craig Mitton, Cam Donaldson, Angela Bate, Madeleine Murtagh
}

Doctors and managers have to make tough decisions about what services to provide from their budgets. Economic approaches can help, but they also need to take into account the practical and ethical challenges faced by healthcare professionals

Cancer Control Research, British Columbia Cancer Research Centre, Vancouver, BC, Canada V5Z 1L3 Stuart Peacock senior research scientist in health economics

School of

Population and Health Sciences, University of Newcastle upon Tyne NE2 4AA

Danny Ruta senior lecturer in epidemiology and public health

Cam Donaldson Health Foundation chair in health

economics

Angela Bate

research associate in health economics

Madeleine Murtagh lecturer in social science and public health

Faculty of Health and Social

Development,

University of British

Columbia

Okanagan,

Kelowna, Canad

Craig Mitton

assistant professor

Correspondence to:

S Peacock

speacock@bccrc.ca

BMJ 2006;332:482-5
Doctors and managers in hospitals and primary care have to manage competing claims on their limited budgets. They have to decide what services to fund and what not to fund as well as the extent of funding. Extra resources will not remove the fundamental need to make such choices because healthcare needs and wants will always outstrip the resources available. Economic approaches to resource management at the local level have had limited success, partly because economists have failed to consider properly the practical challenges that managers and doctors face in making rational priority setting decisions. ${ }^{1}$ Ruta and colleagues described an approach called programme budgeting and marginal analysis, which they argue recognises the need to balance clinical autonomy with financial responsibility. ${ }^{2}$ We describe two checklists to aid managers and doctors in implementing local frameworks for resource management based on this approach. These checklists deal with pragmatic and ethical considerations that are central to the successful design and implementation of priority setting processes.

\section{Why do we need an economic approach?}

The challenge of setting health service priorities is greater than ever. In the United Kingdom, despite the Wanless recommendation for up to a £29bn (43\%) real increase in health spending over five years ${ }^{3}$ many primary care trusts are overspent, with the total deficit estimated to be $£ 500 \mathrm{~m}(\$ 870 \mathrm{~m} ; € 727 \mathrm{~m})$ in $2005 .{ }^{4}$ At the same time, important questions remain as to what managers and doctors are meant to do with national health technology guidance in their local contexts of resource management. ${ }^{5}$ There is a missing link between priority setting at national and local levels. This is highlighted in the United Kingdom by the absence of guidance on how managers and doctors are to commission effectively ${ }^{6}$ and by the relatively poor record of the NHS in implementing evidence from economic appraisals at the local level. ${ }^{7}$

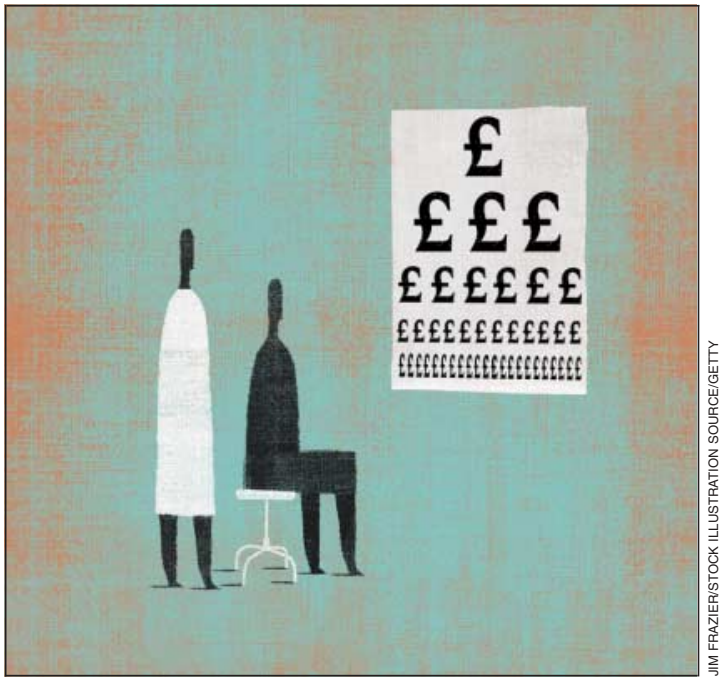

\section{Setting local priorities}

Economists' approaches to setting priorities are based on the costs and benefits of health services, using the principles of opportunity cost and marginal analysis. ${ }^{8}$ The basic principle is that to do more of some things we have to take resources from elsewhere, by either doing the same things at less cost or reallocating resources from other areas of care. This requires accurate measurement of the costs and benefits of healthcare programmes.

These approaches have been applied to some degree at the national level, such as in the health technology appraisals of the UK's National Institute of Health and Clinical Excellence and the pharmaceutical benefits scheme in Australia. However, surveys in the United Kingdom, Canada, and Australia have shown local managers and doctors have limited awareness of economists' tools that could help them set priorities, although they would prefer to work with such tools. ${ }^{9-11}$ 
Programme budgeting and marginal analysis offers a pragmatic framework to help managers and doctors to set priorities that obtain maximum patient benefit from limited resources. ${ }^{8}$ Programme budgeting and marginal analysis has seven stages (box 1). ${ }^{2}$ An important message from programme budgeting and marginal analysis is the need for economic analysts to be practical and not expect managers and doctors to take up mechanistic approaches to priority setting. It reflects the need for a more holistic economic approach to resource management. ${ }^{12}{ }^{12}$ If doctors and managers are to use an economic approach to setting priorities it needs to consider a range of pragmatic and ethical issues.

\section{Pragmatic considerations}

Pragmatic considerations reflect the practical challenges that managers and doctors face in managing resources and will determine whether the priority setting process results in actual changes to the amounts and types of health care provided. They relate to establishing organisational objectives, understanding organisational context and ensuring organisational readiness, establishing an appropriate advisory panel, and ensuring that the implementation of results is feasible (box 2). ${ }^{1} 1213$

The objectives of the organisation (health authority, commissioner, provider, etc) should be established at the outset. Establishing these objectives requires careful consideration of three inter-related issues. Firstly, managers and doctors within the organisation may have multiple objectives-for example, clinical effectiveness, equity, or cultural appropriateness. Secondly, objectives should reflect local priorities but also be compatible with national and regional policies. Thirdly, organisations will have different short and long term objectives.

Perhaps the strongest challenge to any explicit, evidence based priority setting process is that of organisational context and behaviour. Strong management leadership and clinical champions are required for success. Priority setting should occur in a context of relative organisational stability (noting that flux is the norm rather than the exception in health services), with some degree of coherence in long term strategies for planning across health services. Institutional boundaries, such as separate budgets for different types of services, should be clearly established. A key question is whether stated objectives are achievable within current institutional boundaries. If not, the objectives should be revised in the short term. Incentive and sanction mechanisms, including remuneration and funding mechanisms, should be identified, and their potential impact on resource management decisions examined.

International experiences have highlighted the central role of the advisory panel in setting priorities. Its role is to make recommendations for reallocating resources to better meet organisational or health system objectives. ${ }^{12} 13$ An advisory panel comprises key stakeholders in the priority setting process: individuals from relevant clinical and non-clinical disciplines and the community. Stakeholders may include those directly involved in the programmes being considered (doctors, managers, and consumer
Box 1: Stages in priority setting using programme budgeting and marginal analysis

Determine the aim and scope of the priority setting exercise-Will the analysis examine changes in services within a given programme or between programmes?

Compile a programme budget-The resources and costs of programmes combined with activity information

Form a marginal analysis advisory panel-The panel should include key stakeholders (managers, clinicians, consumers, etc) in the priority setting process

Determine locally relevant decision making criteria-The advisory panel determines local priorities (maximising benefits, improving access and equity, reducing waiting times, etc) with reference to national, regional, and local objectives

Identify where services could grow and where resources could be released through improved efficiency or scaling back or stopping some services-The panel uses the programme budget along with information on decision making objectives, evidence on benefits from service, changes in local healthcare needs, and policy guidance to highlight options for investment and disinvestment

Evaluate investments and disinvestments-Evaluate the costs and benefits for each option and make recommendations for change

Validate results and reallocate resources-Re-examine and validate evidence and judgments used in the process and reallocate resources according to cost-benefit ratios and other decision making criteria

representatives) and those indirectly involved (collaborating providers, policy makers, finance and information staff, and community representatives). The advisory panel should receive training in the principles of priority setting to ensure that members have ownership of the process. Community stakeholders have an important role in ensuring decisions reflect the community's values and needs. However, including community members will not guarantee that community views are fully reflected because of the problems of tokenism (do they have a real influence?), representa-

\section{Box 2 Checklist for pragmatic considerations in priority setting}

\section{Establish the organisational objectives}

- Multiple objectives (effectiveness, equity etc; trade-offs between objectives)

- Hierarchical objectives (provider, local, regional, and national levels)

- Inter-temporal objectives (short and long term)

Ensure the organisation is ready for change

- Develop leadership and ownership (managers, providers, consumers, community)

- Consider timing and stability (organisational reforms)

- Identify institutional boundaries (budgetary, service fragmentation or integration)

- Establish incentive and sanction mechanisms (financial, managerial)

\section{Establish an appropriate advisory panel structure}

- Recruit members representing all stakeholders (service managers, providers, consumers, community)

- Identify roles and responsibilities (values, decision making criteria, evaluation of services)

- Train key stakeholders

- Community participation (community values, specific needs)

Ensure that implementation of results is feasible

- Is there a desire to reallocate resources? (ownership)

- Will institutional boundaries allow reallocation?

- How well are funding and priority setting mechanisms integrated? 
tiveness (can they speak for the whole community?), involving the same people all the time, and professionalisation (community members assimilate the professional culture during the process). ${ }^{14}$

The results of priority setting will be implemented only if a decision making culture that considers costs, outcomes, and trade-offs between alternative uses of scarce resources has been established. Managers and doctors must accept the key concepts that underpin programme budgeting and marginal analysis and other economic approaches to priority setting. Successful application of priority setting methods requires a degree of integration between funding and priority setting mechanisms. If priority setting mechanisms conflict with funding mechanisms at local or regional levels, or with budget setting mechanisms within provider organisations, priority setting is unlikely to lead to changes in the allocation of resources.

\section{Ethical considerations}

Stakeholders within health services and the wider community will want to know that the decisions making process was fair. ${ }^{15}$ One approach, and probably the most widely promoted, to addressing fairness in priority setting is Daniels and Sabin's ethical framework of accountability for reasonableness. ${ }^{16}$ Under this framework, a priority setting process is considered to be fair if it satisfies the four conditions relating to publicity, relevance, appeals, and enforcement. We used these as the basis for our checklist for ethical considerations (box 3).

One way in which ethical considerations can be incorporated into a resource management process is to interview or survey relevant stakeholders after the results have been implemented. The accountability for reasonableness framework has been successfully used in this way to evaluate programme budgeting and marginal analysis. ${ }^{1}$

Alternatively, the conditions of accountability for reasonableness could be an integral part of the design of a priority setting process, so that ethical evaluation is conducted alongside economic appraisal. Fairness and openness in the process can improve the perceived credibility of decisions, which may help to mitigate practical problems arising from resources being shifted from one service to another.

This type of focus on fairness in priority setting relates to how decisions are made and does not bypass the need to engage with core economic principles that

\section{Box 3: Checklist for ethical considerations in priority setting}

Ensure publicity of priority setting processes-Make the priority setting processes and decisions, and the rationales behind them, accessible to managers, doctors, patients, and the public

Ensure relevance of priority setting processes-The rationales for priority setting processes and decisions should be based on principles, reasons, and evidence that managers, doctors, patients, and the public can agree are relevant

Establish an appeals mechanism-The mechanism should allow people to challenge decisions and facilitate resolution of disputes, if necessary by revising decisions in light of further evidence

Establish an enforcement mechanism-Voluntary or public regulation mechanisms should be established to ensure that the first three conditions are met

\section{Summary points}

Managers and doctors have to prioritise competing claims on their limited budgets from national guidance, regional and local policy, and their community

Economic approaches can help, but they also need to take into account the practical and ethical challenges faced by healthcare professionals

The practical challenges managers and doctors face will determine whether priority setting results in reallocation of resources

The process should be seen as fair through transparency and accountability

underpin resource management decisions (why those decisions are made). Decision makers need to be able to explain both why and how particular decisions are made. ${ }^{17}$ We would argue that an approach to priority setting based both on economic principles and a fair process is desirable.

\section{Conclusions}

We have described checklists for pragmatic and ethical issues that managers and doctors need to consider before undertaking a priority setting exercise. Both checklists should be considered as an integral part of the design and implementation of economic approaches to setting local priorities, and potentially at other levels of decision making. At the local level, programme budgeting and marginal analysis offers a transparent and robust tool for managers and doctors to use in setting priorities and managing resources, based on economic principles.

We have not discussed the economic considerations in local priority setting at local level. Decisions should, of course, be based on rigorous economic data. Nevertheless, even if relevant, timely, and accurate evidence on costs and benefits is generated as part of the priority setting process, resources are unlikely to be shifted unless the pragmatic and ethical considerations are adequately addressed. Many challenges remain for managers and doctors in the successful design and implementation of priority setting processes at the local level. Perhaps the most important challenges lie in incorporating organisational context and ethics into economists' approaches to priority setting, while making economics an integral part of managers and doctors' management processes.

Contributors and sources: The checklists were devised by synthesising evidence and experiences from an earlier systematic review of the programme budgeting and marginal literature; our experiences of conducting or evaluating about 30 such studies in the United Kingdom, Australia, and Canada; and conducting over 70 priority setting workshops with managers and doctors in the past 15 years. SP took primary responsibility for preparing the manuscript and is guarantor. $\mathrm{DR}, \mathrm{CM}, \mathrm{CD}, \mathrm{AB}$, and MM made multidisciplinary contributions.

Competing interests: None declared.

1 Mitton C, Donaldson C. Priority setting toolkit: a guide to the use of economics in healthcare decision making. London: BMJ Books, 2004. 
2 Ruta D, Mitton C, Bate A, Donaldson C. Programme budgeting and marginal analysis: bridging the divide between doctors and managers. $B M$ J 2005;330:1501-3

3 Wanless D. Securing our future health - taking a long-term view. London: HM Treasury, 2002.

4 Martin D, Lloyd I. Half a billion and counting: the NHS's black hole revealed. Health Serv J 2005 Jan 6:12-5.

5 Health Committee. Second report of session 2001-02 on the National Institute For Clinical Excellence. Vol 1. Report and proceedings of the committee (HC 515 I). London: Stationery Office, 2002

6 Smith J, Mays N, Dixon J, Goodwin N, Lewis R, McClelland S, et al. A review of the effectiveness of primary care-led commissioning and its place in the NHS. London: Health Foundation, 2004.

7 MacDonald R. Using health economics in health services: rationing rationally? Buckingham: Open University Press, 2002.

8 Mooney G, Gerard K, Donaldson C, Farrar S. Priority setting in purchasing: some practical guidelines. Scotland: National Association of Health Authorities and Trusts, 1992. (Research paper No 6.)

9 Miller P, Parkin D, Craig N, Lewis D, Gerard K. Less fog on the Tyne? Programme budgeting in Newcastle and North Tyneside. Health Policy 1997;40:217-29.
10 Mooney G, Wiseman V. Listening to the bureaucrats to establish principles for priority setting. Sydney: SPHERe, University of Sydney, 1999

11 Mitton C, Donaldson C. Setting priorities in Canadian regional health authorities: A survey of key decision makers. Health Policy 2002;60:39-58 12 Peacock S. An evaluation of programme budgeting and marginal analysis applied in south Australian hospitals. Melbourne: Centre for Health Programme Evaluation, Monash University, 1998.

13 Mitton C, Peacock S, Donaldson C, Bate A. Using PBMA in health care priority setting: description, challenges and experience. Appl Health Econ Health Policy 2003;2:121-34.

14 Murtagh MJ, Cresswell P. Ageing and inequalities: tackling inequalities in older peoples' health in the north east of England. Stockton: Northern and Yorkshire Public Health Observatory, 2003.

15 Ham C, Coulter A. Explicit and implicit rationing: taking responsibility and avoiding blame for health care choices. J Health Serv Res Policy and avoiding

16 Daniels N, Sabin J. The ethics of accountability in managed care reform. Health Aff (Milwood) 1998;17:50-64.

17 Hope T, Reynolds J, Griffiths S. Rationing decisions: integrating cost-effectiveness with other values. In: Rhodes R, Battin MP, Silvers A, eds. Medicine and social justice. New York: Oxford University Press, 2002. (Accepted 14 October 2005)

\section{Child health}

\section{Overuse of institutional care for children in Europe}

\section{Kevin Browne, Catherine Hamilton-Giachritsis, Rebecca Johnson, Mikael Ostergren}

Children in institutional care are at risk of attachment disorder and developmental delay, but Europe still relies heavily on this form of care for children in adversity

A minority of children live without their parents, either because their biological parents have died or abandoned them or because their parents do not have the means to care for them appropriately. Under the United Nations' Convention on the Rights of the Child all 52 countries in the World Health Organization's European region agreed to provide children in need with temporary or permanent substitute care. Substitute care varies from institutional care to forms of family based care, such as guardianship by relatives or friends, fostering, or adoption. The services that have been offered have changed over time and have been influenced by political, economic, and social changes.

\section{Institutional care is commonplace}

The recent special issue of the $B M J$ on Europe in transition identified the problems associated with the reform of healthcare systems from centralised state bureaucracies to health insurance and market led services. The editorial on mental health in post-communist countries highlighted the overuse of institutions for people with mental health problems and intellectual disability and the lack of a public health approach involving primary care and community services. ${ }^{1}$ A recent survey by the University of Birmingham and the WHO regional office for Europe reported overuse of institutional care for young children in need-with and without disabilities. ${ }^{2}$ However, institutional care of young children was not restricted to countries in transition and was common throughout the European region (table). Institutions were defined as residential health or social care facilities with 11 or more children, where children stay for more than three months without a primary care giver. Small institutions had the capacity for 11-24 children and large institutions 25 or more children, regardless of age. ${ }^{2}$

The recent WHO initiative on the prevention of child abuse ${ }^{3}$ expressed concern about the lack of com- munity services to uphold the child's right to grow up in a family environment. National child protection policies and legal procedures to rescue children from abuse, neglect, and abandonment have sometimes developed piecemeal and not in parallel with primary care strategies for prevention of abuse and alternative family based care. Thus, in some countries, not enough surrogate family placements are available, so that children may be placed in institutions for long periods.

\section{Is the evidence of harm being ignored?}

More than 50 years of research provides convincing evidence that institutional care is detrimental to the cognitive, behavioural, emotional, and social development of young children. ${ }^{4-6}$ Improvements are seen in cognitive ability when children are removed from institutional care at an early age and placed in a family. ${ }^{67}$ However, institutional care has a lasting impact on behavioural and social development, even when a child is later placed in a supportive family. ${ }^{8-10}$

Children in institutional care rarely have the opportunity to form an attachment to a parent figure/

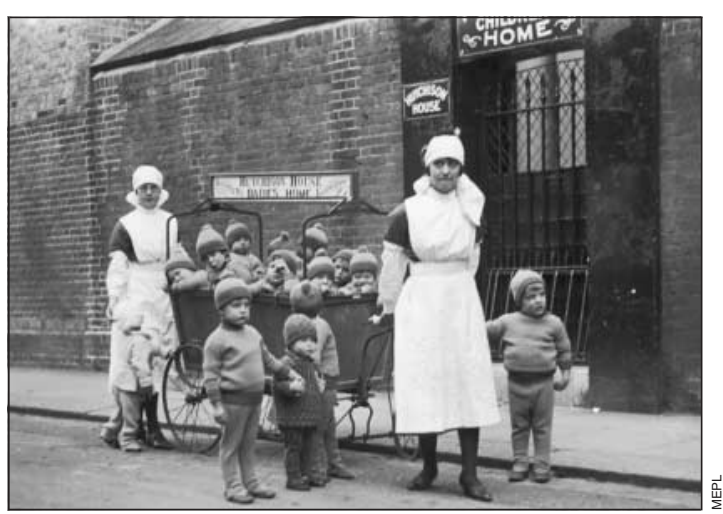

Centre for Forensic and Family Psychology, University of Birmingham, Birmingham B15 2T1

Kevin Browne centre director Catherine Hamilton-Giachritsis senior lecturer Rebecca Johnson research fellow WHO Regional Office for Europe, Copenhagen, Denmark

Mikael Ostergren regional adviser for child and adolescent health and development

Correspondence to: K Browne K.D.Browne@ bham.ac.uk

BMJ 2006;332:485-7 